\title{
Strategies for the sustainable urban waterfront
}

\author{
B. Niemann \& T. Werner \\ Faculty of Architecture and Design, \\ Wismar University of Applied Sciences, Germany
}

\begin{abstract}
In recent years, cities have realized the representative and spatial contextualizing importance of water: Water creates spaces with great conditions to decelerate and stroll. It enlivens and structures urban spaces, without creating spatial borders. It enhances the value of urban spaces and can define a certain image in people's mind maps. A particular focus is set by the revitalization of urban waterfronts or former ports and qualitative enhancement of their spatial condition values: especially, if massive urban conversions take place and new (housing) districts transform the urban heritage. Hereby, the development of the areas at the waterfront has major importance enabling an appropriate insertion of human activities and agglomerations in an increasingly threatened and deteriorating environment. At the same time, the sustainable development of the waterfront can improve the chances of the respective cities and regions in the international competition. First, this paper is dedicated to the relationship of waterfront, city and sustainability. Then criteria are developed, which are crucial for a sustainable urban development at the waterfront. These criteria are clarified by examples of planning practice.

Keywords: waterfront, sustainability, urban development, urban conversion, urban heritage, urban design, revitalization, transformation.
\end{abstract}

\section{Introduction}

The 21st century city is confronted by an unknown number of challenges, which have to be answered: challenges like recycling ground and its efficient use, condensing urban structures, the structural change and in particular sustainability in an ecological, economical and social way. With it, urban spaces have to be designed and configured qualitatively as spaces for socializing and communication, which accommodate a variety of utilizations and offer individual 
living concepts. Between globalization and the protection of individual identities, cities have to create strategic visions of their own urban heritage continuation.

Finally, areas at the waterfront are the last urban fields of experimentation near the city center, whose urban design has to fulfill the mentioned challenges and are able to set new impulses. The newly created districts at the waterfront are frequently marked by iconic architectures, parks and promenades. These districts are already centered within the urban heritage. The urban development at the waterfront also represents the "starting point for the regeneration of the city itself and its relocation in the international context" [1].

Considering the positive effects of urban development at the waterfront, the question arises how attractive areas at the shoreline can be established and satisfy the needs of a sustainable development. In order to find answers, the terms waterfront and sustainability are studied and their meaning for the contemporary urban design will be further examined.

\section{Waterfront, sustainability, urban development}

\subsection{The phenomenon of urban waterfront}

The urban waterfront can be understood as the "part of a town that is next to an area of water such as a river or the sea" [2] and therefore as "the interface between land and water" [1]. Additional descriptions of the term are due to the "gap between the city and the sea" [1] or paraphrase the waterfront as "space for interaction between two different systems - land and water" [1]. The following has to be recognized: "the waterfront should not be simply considered as a line, but should be more correctly envisaged as a network of places, functions, additions and hinges between the coast and the city, between the port and urban activities". [3].

In recent centuries, these often waterside inner city areas were especially used for harbors and by the industry. Increasingly, since the mid-20th century these areas became unused and transformed into derelicts in the city center. Reasons are the arising of container shipping and the relocation of harbors to non-urban areas, as well as the structural change in the western industrial nations and the associated deindustrialization. Simultaneously, new chances and potentials of urban condensing and progression have revealed. Since the 1960s, the waterfront has again become a spatial significance by being realized as a resource of urban design [4]. In addition, the waterfront is a natural asset that is particularly valuable, but limited and non-renewable. Also, areas near the water gain a sense attractiveness and recreational value for people. This is why both, city dwellers and tourists seek to be close to the water.

For urban design, the value of the waterfront means that varied urban spaces have to be created, which allow diverse uses of the waterfront. The water has to be used with all of its plurality: It should not only be used to compose geometries of urban spaces, but its characteristics and the particularities of circulating have to be integrated in the design proposal. 
Harbors overcome their former use and become part of the existing city center. Thereby, the center expands and sites at the waterfront are offered to the inhabitants of the city. The water is a symbol for living quality and an exceptional location within the city context and the surrounding region.

The development of the waterfront is considered as one of the most significant and comprehensive tasks of contemporary urban design. In this field architectural and urban experiments can be combined with ecological, economic and social sustainability intentions.

\subsection{Sustainable development}

Our modern understanding of sustainability or sustainable development is based on the report "Our Common Future", which was published by the Norwegian prime minister Gro Harlem Brundtland 1987 and the World Commission for Environment and Development of the United Nations in 1987 (also known as the "Brundtland-Report"). The original definition is: "Sustainable development is development that meets the needs of the present without compromising the ability of future generations to meet their own needs." [5]. This understanding of sustainable development became common language due to the United Nations Conference on Environment and Development in Rio de Janeiro in 1992 (also known as the "Rio-Conference"). In addition to the awareness of the existing environmental risks the concept of sustainable development represents a principle of action that tries to combine ecological, economic and social objectives [6].

The Agenda 21 was determined at the Rio-Conference and recommends a creative, integrated approach to ensure sustainable development. After its publication of the Agenda 21, the participating nations included the ecological carefulness, the social equity and economic efficiency in their decision-making processes [6]. From now on, the premise of sustainability should be governing any people's action - as well as in the disciplines of architecture, urban development and urban planning.

Similarly, sustainable urban development at the waterfront has to lead to improved living conditions for the city`s inhabitants. Hereby, ecological, economical and social goals have to be combined. A sustainable waterfront is "a place where people from all backgrounds and ages can live, work, play, visit, and learn in a way that strengthens and celebrates the beauty, the diversity, the economic vitality, the opportunities, the creativity, the heritage, and the natural environment of the city" [7]. Furthermore: "The popular sign of success of many waterfronts development is bringing citizens and visitors back to the water's edge, and providing tangible evidence of the continuing vitality of the cities" [8]. For that, waterfront urban design has to fulfill a lot of requirements. The following criteria are picked up and discussed in the scientific literature.

\subsection{Criteria for a sustainable urban development at the waterfront}

The basic precondition for the successful development of a city's waterfront is the protection of the environment. Areas next to the water are elementary parts of the world's ecosystem. On the one hand the natural ecosystem has to be preserved 
and on the other, its present status has to be enhanced. Especially such areas, which were used for industry offer potentials to enhance this status today [1]. The protection of the environment can also be supported by the minimizing of future energy consumption and recycling of resources [9].

Also the new waterfront has to be understood as an integral part of a city's urban structure [1]. The waterfront cannot be a competitor of the city, but it has to complete the urban structure and the other way around. At the same time, it is necessary to unite the existing urban heritage and new development [2].

Therefore, the conservation of the Genius Loci, the historic spirit of a certain space, and the currency of the industrial appearance are important for sustainable development [1].

By settling diverse usages at the waterfront different types of users will be attracted [3]. The district, which has to be developed, should offer a multiplicity of cultural, social and commercial facilities as well as a diversity of living concepts. This balanced form of mixing utilizations has to be implemented in the scale of the whole new district and translated to the single floor plans of the buildings.

In the end, the public space is also important for the sustainable development of the waterfront district. Parks, green areas, squares und promenades have to be designed qualitatively and have to be accessible for the inhabitants and visitors at any time. In order to configure attractive public spaces, it is important to conserve old and add new axes of view between the existing city and the water through the new district [2].

Additional to these guidelines of urban design, a lot of strategic specifications have to be followed in order to develop the waterfront sustainably. Priority is given to the including of the city's society in the planning process. Citizens need to be kept informed from the beginning and especially involved in discussions, so that a real active citizenship can be implemented and the city can benefit from the development of the waterfront socially [1].

Furthermore, waterfront projects require a long-term implementation [10]. They often represent a challenge for more than one generation. Stakeholders of these projects - among others: the city council, investors, developer, entrepreneurs - are responsible to support the realization of the projects regardless of the general economic situation over time [6].

Nevertheless, masterplans have to offer flexibility in order to relate to shortterm changes, like a change in the demand for housing [1].

The transfer of knowledge and experience can be conductive for a sustainable development [1]. International networks can be helpful in order to bring stakeholders together, who will be enabled to support and learn from each other.

The multiplicity of enumerated criteria shows the difficulty of the challenging task to develop a sustainable waterfront clearly. Subsequently, international goodpractice-projects, which try to fulfill the illustrated goals, will be described. 


\section{International examples}

Studying international examples carefully and critically led to the insight, that there is no project, which fulfills all of the mentioned criteria satisfactorily. Therefore, the following descriptions are categorized by the projects main quality. Due to the main characteristics of the projects, they largely emphasize the influence of sustainable criteria in the strategic conception of a sustainable waterfront.

\subsection{Protection of the environment}

Due to the relocation of former industrial and military land use areas, Berlin possesses a lot of derelict areas near inner city watersides. The early 1990s were the starting point for the revitalization of the waterfront in Berlin. The following projects "Wasserstadt Oberhavel" in Spandau and the "Rummelsburger Bucht" need to be mentioned here. Planners placed a high value on the preservation and maintenance of the woods, parks and green areas [1]. A consequent development was the water plan development at the beginning of the 21 st century. It highlights a total of 21 potential restructuring areas at the waterfront. The project's goals are the improvement and the cultivation of the urban green structures and renewal of the balance between nature and built environment [1].

Additional waterfront projects which have been planned and developed since the millennium are characterized by an energy efficient approach. Especially notable in this context are the waterfront projects in Copenhagen, Amsterdam and Fredericia.

\subsection{The waterfront as an integral part of the cities' urban structure}

A characteristic attribute of sustainable waterfront development in Fredericia, Denmark is its integration in the urban structure. Frederica's history as a garrison city is still apparent today: The city still has intact vaults and the typical grid-like layout of the renaissance city. This grid is used between water and city center as an urban design tool, creating an extended network of canals and paths [11]. The result is a new urban structure which is integrated in the old and refers to its dimensions and historical context.

\subsection{Preservation of the historical identity and character}

The waterfront in Auckland, New Zealand has accommodated industry, a harbor, dockyards, warehouses, gas stations, large infrastructure and railway tracks since the $1880 \mathrm{~s}$. When revitalizing the waterfront in 2005, planners decided to preserve relics of the industrial past in the Wynyard District. Nowadays, the silo park's icon is the restored cement silo, whose environment is the venue for cultural events [12]. In addition, former shipping containers were arranged on the site to accommodate the tourist information. The industrial character was not only maintained, but old and new has now been correlated in a historical context. 


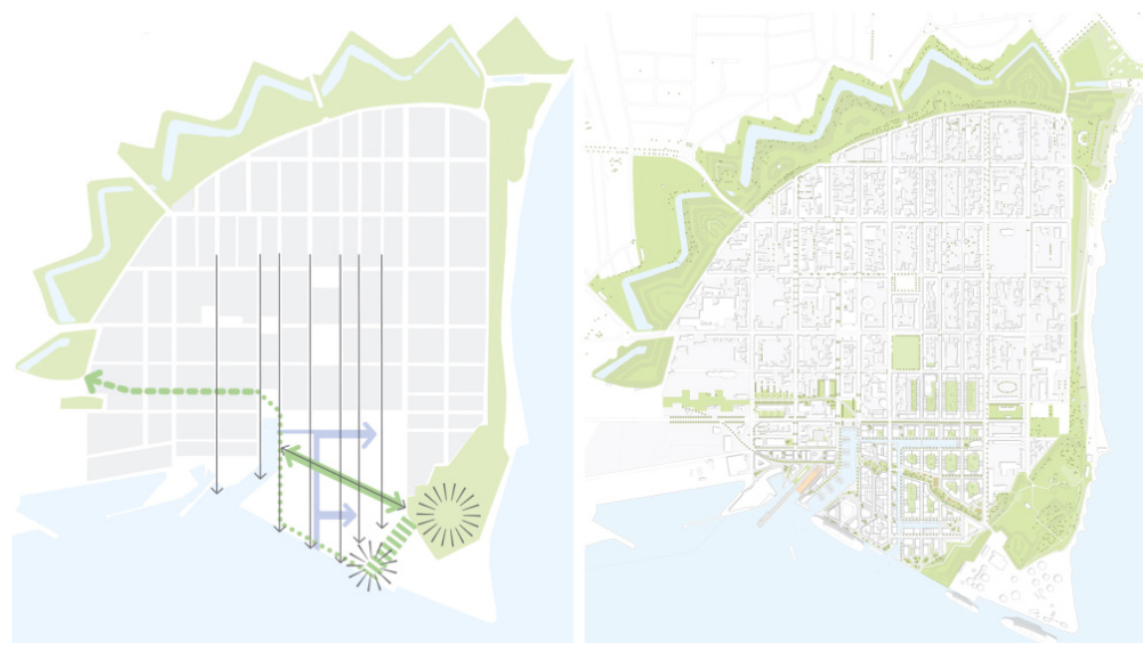

Figure 1: $\quad$ Site plan Fredericia [17].

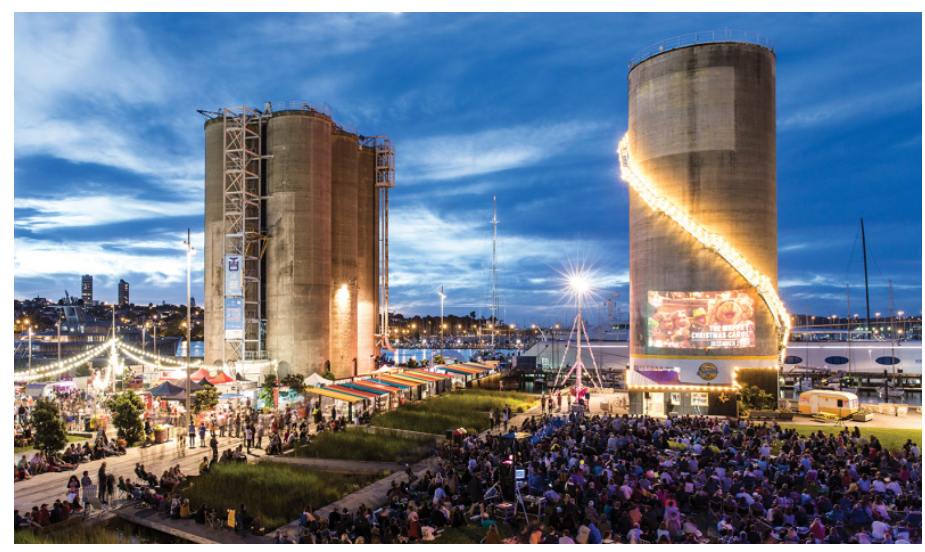

Figure 2: $\quad$ Silo Park Auckland [18].

\subsection{Mix of different uses}

Die HafenCity Hamburg is characterized by the principle of the mix of uses. Therefore, the district is divided into quarters, which are dedicated to certain categories of uses. For example, the "Oberhafen" is formed as a place of creativity and culture. The commercial center of the HafenCity is based on the "Überseequartier". Also within these quarters, different uses are united. In the "Elbtorquartier" residential areas have developed alongside offices, retail, gastronomy, hotels, services and science. But this type of use mix is not only prevalent in the district and its quarters. The "Katahrinenschule" accommodates the elementary school, a kindergarten and housing. The new buildings at the 
"Strandkai" will house residential, services, retail, gastronomy and culture. Retail or dining are based on ground floors of the most of the residential buildings in the district.

\subsection{Public space}

One of the most important waterfront projects of the 1960s is the "Inner Harbor" in Baltimore, USA. The former industrial harbor had become derelict and should have been transformed into a destination for inhabitants and tourists. For this purpose, a public promenade was created, whose environment is characterized by newly created public spaces, like public gardens and parks. These new public spaces were popular and attracted new companies, hotels and museums to the site [13]. The mobility supple was expanded by a new water taxi service [14]. In order to sustain the importance of the urban spaces Baltimore's waterfront, the plan "Baltimore Inner Harbor 2.0" [15] was adopted. The continuation and expansion of the central promenade and the related public space were the main focal points of the plan.

\subsection{Active citizenship in the planning process}

A lot of waterfront projects are determined by a top down controlling, which leads to a late public involvement in the planning process [16]. However, this participation can often not be called active citizenship. The public is mostly informed but not involved: Active discussions and collaboration within the decision process does not take place [16]. For future revitalizations a culture of active citizenship in the beginning of the process has to be implemented.

\subsection{Long-term planning}

The previously mentioned project in Baltimore has highlighted the long-term nature of waterfront projects. Another example is the waterfront of Toronto, which is the biggest revitalization project of northern America. The planning started in the early 1970 s and was determined by small dimensioned residential projects. Nowadays planners try to implement a sustainable development by formulating an overall concept for the waterfront [14]. Additional projects have adopted this longterm nature and have to be realized step by step. Other examples are the waterfront projects in Auckland, Barcelona and Genoa.

\subsection{Flexibility of masterplans}

The HafenCity in Hamburg is again a good example. The development of the site has continued for 25 to 30 years and a lot of conditions have changed in this period. Therefore, a masterplan facilitates a helpful flexibility. Accordingly, it is based on abstract goals, which constitute a flexible framework. On the one hand it gives a certain orientation and on the other hand it allows alternative interpretations. The flexibility of the masterplan enabled the planners to implement a modified planning for the eastern part of the waterfront site, ten years after the starting of 
the development. The need to adapt the planning resulted from an increased demand for multi-story apartments in the center of Hamburg.

\section{Conclusions}

The examined cities ignored the potential of the waterfront over time. The reasons for this were already widely discussed within scientific debates. In order to develop an individual and iconic cityscape and attractive locations, the water related urban landscape was rediscovered. They are considered as a catalyst of sustainable development. City's try to integrate the development of their waterfront into development planning's for the whole city center or even city. Examples are Auckland, Baltimore, Barcelona, Genoa, Liverpool, Marseille, Saragossa and Shanghai.

The examples represent only a fragment of the spectrum of urban waterfront projects. Nevertheless, insights of how to implement sustainable urban development by the water have been pointed out. A particular need for improvement has been identified in the active citizenship within planning processes. A holistic sustainable solution at all layers of sustainability has to be purposed in order to fulfill the criteria of sustainable urban development at the waterfront.

\section{References}

[1] Giovinazzi, O. \& Moretti, M., Port Cities and Urban Waterfront: Transformations and Opportunities, TeMaLab Journal of Mobility, Land Use and Environment, 3, pp. 57-64, 2010

[2] Hussein, R.M.R., Sustainable Urban Waterfronts Using Sustainability Assessment Rating Systems, International Journal of Civil, Environment, Structural, Construction and Architectural Engineering, 8(4), pp. 488-498, 2014

[3] Giovinazzo, O. \& Giovinazzi, S., Waterfront planning: a window of opportunities for post-disaster reconstruction. Proceedings of the $4^{\text {th }}$ International i-Rec Conference - Building resilience: achieving effective post-disaster reconstruction, Rotterdam, pp. 178-193, 2008

[4] Schubert, D., Revitalisierung von brachgefallenen Hafen- und Uferzonen. Transformationsprozesse an der urbanen Waterfront, Raumforschung und Raumordnung, 90(1), pp. 48-60, 2001

[5] United Nations World Commission on Environment and Development, Our Common Future, Oxford University Press, Oxford, 1987

[6] Gauzin-Müller, D., Nachhaltigkeit in Architektur und Städtebau: Konzepte, Technologien, Beispiele, Birkhäuser: Basel, Berlin and Boston, 2002

[7] Toronto Waterfront Revitalization Cooperation, Sustainability Framework, 2005, Online. http://www.waterfrontoronto.ca/dbdocs/4a1 fe4722fcae.pdf

[8] Hoyle, B., Waterfront revitalization in East African port-cities, Cities, 18(5), pp. 297-313, 2001 
[9] El. Deeb, S., Abel Galil, R. \& Sarhan, A., A Sustainability Assessment Framework for Waterfront Communities, Arab Academy for Science \& Technology \& Maritime Transport, Egypt, 2011 http://gccbs2013.aast.edu /newgcc/images/pdf/a\%20sustainability\%20assessment\%20framework\%2 0 for $\% 20$ waterfront $\% 20$ communities.pdf

[10] Salkin, P.R., Integrating Local Waterfront Revitalization Planning into Local Comprehensive Planning and Zoning, Pace Environmental Law Review, 22(2), pp. 207-230, 2005

[11] KCAP Architects and Planners, Fakton, Ramboll, Fredericia C Phase 2, Development Plan, $2011 \mathrm{http}: / / \mathrm{www}$. fredericiac.dk/ /media/fredericiac/ dokumenter/holdenes\%20forslag/fredericiac_kcap-ramboll-fakton submission-phase-2_booklet.ash $\mathrm{l}$ ? $\mathrm{l}=\mathrm{da}$

[12] Waterfront Auckland, The Waterfront Plan 2012, 2011 https://www.waterfrontauckland.co.nz/getmedia/68b631ad-87ef-4501b8cc-3083698b70da/39347-WAKL-Waterfront-Plan_Y.pdf.aspx/

[13] You, N. \& Louwaars, S., Port Cities: Capitalizing on Re-Development with examples from Baltimore, Bilbao and Liverpool. Bollettino del Dipartimento di Conservazione dei Beni Architettonici ed Ambientali, Università degli Studi di Napoli "Frederico II": Napoli, pp. 35-41, 2012

[14] Schubert, D., Transformationsprozesse an der Wasserkante, StadtWasser: Wasserkonzepte für die Stadtgestaltung, Frauenhofer IRB-Verlag: Stuttgart, pp. 79-85, 2010

[15] Waterfront Partnership of Baltimore \& Greater Baltimore Committee, Baltimore Inner Harbor 2.0, $2013 \mathrm{http} / / /$ baltimorewaterfront.com/wpcontent/uploads /2015/06/Inner-Harbor2-0-Master-Plan-compressed.pdf

[16] Smith, H. \& Garcia Ferrari, M., Experiences in Participation in the Port City of Hamburg, Waterfront-Regeneration: Experiences in City-building, eds. Smith, H. \& Garcia Ferrari, M., Routledge: London, New York, pp. 95-114, 2012

[17] Site Plan Fredericia: KCAP Architects and Planners, Fakton, Ramboll, Fredericia C Phase 2, Development Plan, 2011 http://www.fredericiac.dk/ $\sim /$ media/fredericiac/dokumenter/holdenes\%20forslag/fredericiac_kcapramboll-fakton_submission-phase-2_booklet.ashx?la=da

[18] Silo Park, Auckland http://www.tcl.net.au/cms_images/280_18-082014_3208.jpg 